\title{
WEAR RESISTANCE AND SURFACE ROUGHNESS OF TWO TYPES OF MONOLITHIC GLASS-CERAMICS: AN IN VITRO STUDY
}

\author{
Mohamed Abdel-Aziz * and Maha Fouad **
}

\begin{abstract}
Aim: The purpose of this in vitro study was to evaluate the wear resistance and surface roughness of zirconia reinforced lithium silicate glass-ceramic (ZLS) compared to lithium disilicate glass-ceramic after simulated mastication.

Materials and Methods: Thirty samples were prepared and divided according to the material of construction into three groups $(n=10)$. Group (1): E Max-CAD, Group (2): Celtra Duo ZLS, Group (3): Celtra Press ZLS. The sectioned samples of E-max CAD (Ivoclar, Vivadent, Schaan, Liechtenstein) blocks were polished and crystalized. The sectioned samples of Celtra Duo ZLS (Dentsply Sirona) blocks were glazed and fired. The Ingots of Celtra Press (Dentsply Sirona) were lab pressed, sectioned, glazed and power fired. The two-body wear testing was done using a chewing simulator integrated with thermo-cycling. Each ceramic sample was weighed and evaluated for surface roughness before and after the wear simulation test using an electronic analytical balance and optical profilometry, respectively.
\end{abstract}

Results: IPS E-max CAD revealed the highest amount of weight loss with no statistically significant difference between groups as indicated by ANOVA test. The change in weight for each group was non-significant as demonstrated by paired t-test. The roughness mean value for E-max CAD was significantly decreased and recorded the lowest roughness change. Tukey's post-hoc showed a non-significant difference in the roughness mean value between Celtra Duo and Celtra Press. The roughness change for either Celtra Duo or Celtra Press groups was non-significantly increased as demonstrated by paired t-test.

Conclusions: ZLS Celtra ceramics had insignificant less wear and significantly higher surface roughness with enamel antagonist compared to E-max CAD. Although wear and roughness were affected by the surface finishing of glass ceramics, the construction method of ZLS restorative materials had no significant impact on both.

KEYWORDS: Glass ceramics, Zirconia-reinforced lithium silicate, lithium disilicate, chewing simulator, Wear, Surface roughness.

\footnotetext{
* Associate Professor, Fixed Prosthodontics Department, Faculty of Dental Surgery, Ahram Canadian University.

** Lecturer, Fixed Prosthodontics Department, Faculty of Dental Surgery, Ahram Canadian University.
} 


\section{INTRODUCTION}

Due to the endless patients' demands for dental restorations that mimic the natural teeth appearance, there is an increase in using all-ceramic materials. Despite the good aesthetics that are given by ceramic restorations, clinicians were often concerned about their abrasiveness toward natural dentition. Wear activity is an important issue for all dental restorative materials.

Wear in dentistry arises when two articulating surfaces undergo slipping and sliding movements against each other under load application. Occlusal wear of teeth and restorative materials occurs due to the interaction of biological, mechanical, chemical, and tribological factors ${ }^{(1)}$. Ideally, restorative materials can exhibit equivalent wear behavior to that of natural dentition ${ }^{(2)}$. Excessive wear of teeth or restorations may be correlated with opposing teeth supra eruption, periodontal breakdown, traumatic occlusion, loss of vertical dimension, and yet temporomandibular joint dysfunction ${ }^{(3)}$.

Glass-ceramics are commonly used in restoring the anterior and posterior teeth owing to their high esthetic appearance ${ }^{(4)}$. Glass ceramics include leucite, lithium disilicate and lithium silicate ceramics. But the mechanical properties of leucite ceramics were found 2-3 times lower than other types of glass-ceramics ${ }^{(5)}$. Mainly, ceramic is composed of a crystalline phase embedded in a glassy matrix. The incorporation of small crystalline particles bonded to the glass matrix has resulted in increasing the mechanical properties of glassceramics, particularly flexural strength, and fracture toughness ${ }^{(6,7)}$. Furthermore, glass ceramics with higher crystal content reveal greater wear resistance and produce less wear on opposing enamel ${ }^{(8)}$.

These monolithic glass ceramics can be fabricated either by CAD/CAM technology or by heat pressing technique. Lithium disilicate ceramics contain about $70 \%$ platelet-shaped lithium disilicates which are crystallized in the glass phase ${ }^{(9)}$. IPS E max
CAD (Ivoclar Vivadent, Schaan, Lichtenstein) is a lithium disilicate glass ceramic designed for $\mathrm{CAD} /$ CAM which combines good esthetics, high flexural strength, and fracture toughness ${ }^{(10)}$.

Improvement of the properties of glass ceramics has been continued by refining the crystal structure. Zirconia reinforced lithium silicate glass-ceramics (ZLS) comprise lithium metasilicate and lithium orthophosphate. The glassy matrix is reinforced with $10 \%$ by weight zirconium oxide. The nucleating agents used are cerium oxide and phosphorus pentoxide to interrupt crack propagation ${ }^{(11)}$. Celtra Duo (Dentsply, Sirona) is a ZLS CAD/CAM block material made specifically for application with Cerec ${ }^{(12)}$. Celtra press (Dentsply, Sirona) can be pressed in the lab to produce indirect ceramic restorations ${ }^{(9)}$.

Because the glass ceramic restorations are monolithic, they are in contact with enamel antagonist. So, the wear resistance and abrasiveness of these materials are important. The quality of finishing and polishing or glazing the occlusal surface of glass ceramics together with their mechanical properties may affect the surface roughness and wear of both the restorative materials and the enamel $\operatorname{antagonist}^{(13)}$.

The clinical performance of the Zirconia reinforced lithium silicate glass-ceramics is little known regarding their mechanical wear resistance, therefore, in this in-vitro study the surface roughness and wear resistance of Zirconia reinforced lithium silicate glass-ceramics (Celtr Duo and Celtra press) were evaluated in comparison to lithium disilicate glass ceramic (IPS E-max CAD).

\section{MATERIALS AND METHODS}

In the present study, two types of monolithic glass ceramic materials were tested against natural human enamel. These materials with their composition are listed in the table (1). They were lithium disilicate (E-max CAD, Ivoclar, Vivadent, Schaan, Liechtenstein) and zirconia reinforced 
TABLE (1) The tested Materials in the study

\begin{tabular}{|c|c|c|c|}
\hline Material & Classification & Composition & Manufacturer \\
\hline IPS E-max CAD & $\begin{array}{c}\text { Lithium disilicate glass } \\
\text { ceramic }\end{array}$ & $\begin{array}{l}\text { 58-80\% silicon dioxide, } 11-19 \% \text { lithium oxide, } \\
0-13 \% \text { potassium oxide, } 0-8 \% \text { zirconium } \\
\text { dioxide, } 0-5 \% \text { aluminum oxide }\end{array}$ & $\begin{array}{l}\text { Ivoclar Vivadent, } \\
\text { Schaan, } \\
\text { Liechtenstein }\end{array}$ \\
\hline Celtra Duo & $\begin{array}{l}\text { Zirconia-reinforced lithium } \\
\text { silicate ceramic }\end{array}$ & $\begin{array}{l}58 \% \text { silicon dioxide, } 10.1 \% \text { crystallized } \\
\text { zirconium dioxide, } 10 \% \text { zirconium dioxide, } \\
5 \% \text { phosphorous pentoxide, } 2.0 \% \text { ceria, } \\
1.9 \% \text { alumina, } 1 \% \text { terbium oxide }\end{array}$ & $\begin{array}{l}\text { Dentsply Sirona } \\
\text { Hanau- Germany }\end{array}$ \\
\hline Celtra Press & $\begin{array}{l}\text { Zirconia-reinforced lithium } \\
\text { silicate ceramic }\end{array}$ & $\begin{array}{l}59.3 \% \text { silicon dioxide, } 9.3 \% \text { zirconium dioxide, } \\
4.9 \% \text { phosphorous pentoxide, } \\
0.83 \% \text { ceria, } 3 \% \text { aluminum oxide, } 14.5 \% \text { lithium } \\
\text { oxide, } 3.3 \% \text { terbium oxide, } 1.2 \% \text { potassium } \\
\text { oxide, } \mathrm{Na} 2 \mathrm{O} \text {, Magnesium oxide: } 0.01 \%,{ }^{(4)}\end{array}$ & $\begin{array}{l}\text { Dentsply Sirona } \\
\text { Hanau- Germany }\end{array}$ \\
\hline
\end{tabular}

lithium silicate (ZLS) (Celtra, Dentsply Sirona, Hanau- Germany), which is in two forms; Celtra Duo CAD/CAM blocks for CEREC and inLab machines and Celtra Press ingots for pressing in the lab by lost wax technique.

In this study, a total of 30-disc samples were prepared from the three tested ceramic material groups $(\mathrm{n}=10)$. Group (1): E Max-CAD, Group (2): Celtra duo, Group (3): Celtra press.

\section{Preparation of E-Max CAD sample}

Ten-disc samples $(n=10)$ were prepared from E-max CAD blocks $(18 \times 14 \times 12 \mathrm{~mm})$. The block was sectioned to obtain rectangular plates with $1.5 \mathrm{~mm}$ thickness using a water-cooled diamond saw (IsoMet 4000; Buehler, Lake Bluff, USA). All disc samples were cleaned by submerging in an ultrasonic cleaner with distilled water for 10 minutes. Each sample $(1.5 \times 14 \times 12 \mathrm{~mm})$ was then polished with silicon carbide abrasive papers (400-, 600-, 1200-grit papers; 3M) under copious irrigation of water. The specimens were crystallized for $10 \mathrm{~min}$ at $850^{\circ} \mathrm{C}$ using a porcelain furnace (Programat EP 3000, Ivoclar Vivadent) according to the manufacturer's instructions.

\section{Preparation of Celtra Duo sample}

Ten-disc samples of celtra duo CAD blocks were sectioned with the same dimensions $(1.5 \times 14 \times 12 \mathrm{~mm})$ and method like samples of E-max CAD blocks. Then, celtra glaze (Dentsply Sirona) was applied to the entire surface of each disc using a clean brush. All samples were glaze fired at $820^{\circ} \mathrm{C}$, using a porcelain furnace (Programat EP 3000, Ivoclar Vivadent). The firing program and parameters were performed according to the manufacturer's instructions.

\section{Preparation of Celtra Press sample}

The ceramic ingots of celtra press were lab pressed using the lost wax technique to obtain 10disc samples with a thickness of $1.5 \mathrm{~mm}$ following the manufacturer's instructions. A specially designed bisected Teflon mold was machine milled, with a rectangular mold cavity of $14 \times 12 \mathrm{~mm}$ width, to accommodate a molten wax pattern. The Teflon mold was assembled inside a metal cylinder and secured by a screw key. Cylindrical wax patterns $(14 \times 12 \times 10 \mathrm{~mm})$ were constructed using the Teflon mold, sprued and embedded in the ring containing a mixed powder/liquid ratio of investment material (Celtra Press, Dentsply sirona) according to the 
manufacturers 'recommendation. The investment ring was pre-heated at $700^{\circ} \mathrm{C}$ for $30 \mathrm{~min}$, then pressed in a furnace (Programat EP 3000 Ivoclar vivadent). After cooling down to room temperature, the obtained ceramic cylinders were divested and cleaned by air-particle abrasion. They were sectioned to obtain 10 rectangular plates $(1.5 \times 14 \times 12 \mathrm{~mm})$ using a water-cooled low-speed diamond saw (IsoMet 4000; Buehler, Lake Bluff, USA). The 1.5 mm thickness of each obtained disk was confirmed by a digital caliper. All disks were smoothed and cleaned in an ultrasonic cleaner with distilled water. The specimens were glazed with celtra glaze (Universal stain, Dentsply, Hanau, Germany). The recommended glaze firing cycle was called "Power Fire" which increases flexural strength of the Celtra Press restoration to its maximum $>500 \mathrm{MPa}$ as claimed by the manufacturer.

\section{Preparation of enamel antagonist specimen}

Human enamel was used in this study for wear testing against the experimental materials. Recently extracted premolars for orthodontic or periodontal reasons were collected and cleaned from tissue debris. The selected teeth were approximately had equal sizes with no worn-out or fractured cusps. Each tooth was sectioned mesio-distally using a low-speed cutting machine (Low Speed Saw 11e1180; Isomet) into two equal buccal and lingual halves $(n=30)$. The enamel antagonist specimens were firmly gripped by tightening the Jackob's chuck of the upper part of wear simulator.

\section{Measurement of weight samples:}

Wear of material may accompany with the loss of its weight due to continual use ${ }^{(14)}$. So, the weight of each sample was measured before and after wear to calculate the weight loss of each sample. Each sample of the ceramic disc was weighed before wear simulation test using the electronic analytical balance (Sartorius, Biopharmaceutical and Laboratories, Germany) with an accuracy of $0.0001 \mathrm{gm}$. As this electronic balance had a fully automated calibration technology and a micro weighing scale, values of all samples were accurately measured. To ensure accuracy, the balance was kept on a free-standing table away from vibrations and weighed the specimens with the glass doors of the balance closed to avoid the effect of air flows.

\section{Surface roughness evaluation}

The optical profilometry was used for quantitative characterization of surface topography without contact. Quantitative analysis of two-body wear on specimens was carried out before and after wear simulation test using a 3D-surface analyzer system. All specimens were photographed using USB Digital microscope having a built-in camera (U500X, Digital Microscope, Guangdong, China). The microscope is connected to an IBM compatible computer using a fixed magnification of $120 \mathrm{X}$. The images were recorded with a resolution of $1280 \times$ 1024 pixels per image. All images were analyzed using WSxM software (Ver 5 develop 4.1, Nanotec, Electronica, SL) to estimate average of heights (Ra) expressed in $\mu \mathrm{m}$, which can be accepted as reliable indices of surface roughness ${ }^{(15)}$. Then, a 3D image of the surface profile of the specimens was created using a digital image analysis system (Image J 1.43U, National Institute of Health, USA). The non-worn surface served as a reference. With this method, a 3-dimensional geometry of the worn surface was produced.

\section{Wear simulation test}

The two-body wear testing was performed using a programmable controlled ROBOTA chewing simulator integrated with a thermo-cyclic protocol which operated on servomotor (model ach09075dc-t, AdTech technology co., Germany). The simulator has four chambers. Each chamber consists of an upper chuck which holds the tooth antagonist specimen and a lower Teflon holder in which the ceramic specimen was embedded. A weight of $5 \mathrm{~kg}$. comparable to $49 \mathrm{~N}$ of chewing force was exerted with $1 \mathrm{~mm}$ vertical movements, $3 \mathrm{~mm}$ horizontal 


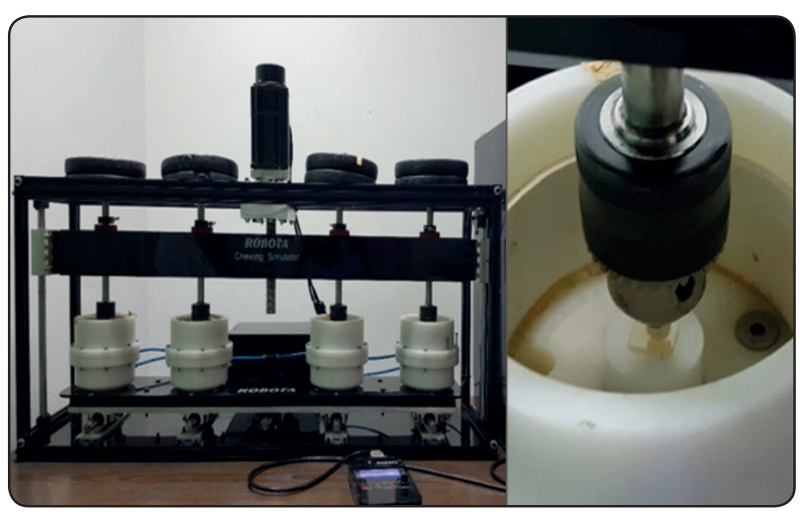

Fig. (1) Chewing simulator used for wear simulation test.

movement and $1.6 \mathrm{~Hz}$ to simulate chewing process. The load application was accompanied with thermocycling which involves immersion in a cold/hot water bath with a temperature deviation of $5^{\circ} \mathrm{C} / 55^{\circ} \mathrm{C}$ and dwell time 60 seconds. The test was repeated 37500 times to clinically simulate 3 months chewing condition ${ }^{(16)}$.

After finishing the test, all samples were cleaned and dried with tissue paper before weighing. Each ceramic sample was weighed again using the electronic analytical balance. Then, calculation of weight loss due to wear was done. Also, the surface roughness of the samples was evaluated after the wear simulation test with the same method and devices used for evaluating the baseline surface roughness.

\section{Statistical analysis}

Data analysis was collected, tabulated, and statistically analyzed in several steps. One-way ANOVA test was done to compare between material groups, followed by pair-wise Tukey's post-hoc tests when the difference was found to be significant. Paired t-test was used to compare difference in weight or roughness values before and after wear simulation. Statistical analysis was performed using (Graph-Pad Prism version 4.00 for Windows, Graph-Pad Software, San Diego California USA). $P$ values $\leq 0.05$ were statistically significant in all tests.

\section{RESULTS}

\section{Weight loss}

The mean values and standard deviations (SD) for wear measured by weight loss (in grams) recorded in all materials before and after 3 months wear simulation cycles summarized in table (2) and graphically represented in figure (2)

TABLE (2) Wear results (Mean values \pm SD) by weight loss for experimental material groups (in grams) before and after wear simulation

\begin{tabular}{|c|c|c|c|c|c|c|c|}
\hline \multirow{2}{*}{\multicolumn{2}{|c|}{ Material group }} & \multirow{3}{*}{$\begin{array}{c}\text { Mean } \\
0.530\end{array}$} & \multirow{3}{*}{$\begin{array}{l} \pm \text { SD } \\
\pm 0.097\end{array}$} & \multicolumn{2}{|c|}{ Paired difference } & \multirow{2}{*}{ Changes \% } & \multirow{2}{*}{$\begin{array}{c}\text { T-test } \\
\text { P value }\end{array}$} \\
\hline & & & & & & & \\
\hline \multirow{2}{*}{$\begin{array}{c}\text { E-Max } \\
\text { CAD }\end{array}$} & Before & & & \multirow{2}{*}{0.035} & \multirow{2}{*}{ \pm 0.066} & \multirow{2}{*}{6.661} & \multirow{2}{*}{$0.148 \mathrm{~ns}$} \\
\hline & After & 0.494 & \pm 0.013 & & & & \\
\hline \multirow{2}{*}{ Celtra Duo } & Before & 0.579 & \pm 0.054 & \multirow{2}{*}{0.011} & \multirow{2}{*}{ \pm 0.007} & \multirow{2}{*}{1.830} & \multirow{2}{*}{$0.346 \mathrm{~ns}$} \\
\hline & After & 0.569 & \pm 0.057 & & & & \\
\hline \multirow{2}{*}{ Celtra Press } & Before & 0.679 & \pm 0.087 & \multirow{2}{*}{0.006} & \multirow{2}{*}{ \pm 0.005} & \multirow{2}{*}{0.864} & \multirow{2}{*}{$0.443 \mathrm{~ns}$} \\
\hline & After & 0.673 & \pm 0.085 & & & & \\
\hline ANOVA & Pvalue & \multicolumn{6}{|c|}{$0.237 \mathrm{~ns}$} \\
\hline
\end{tabular}




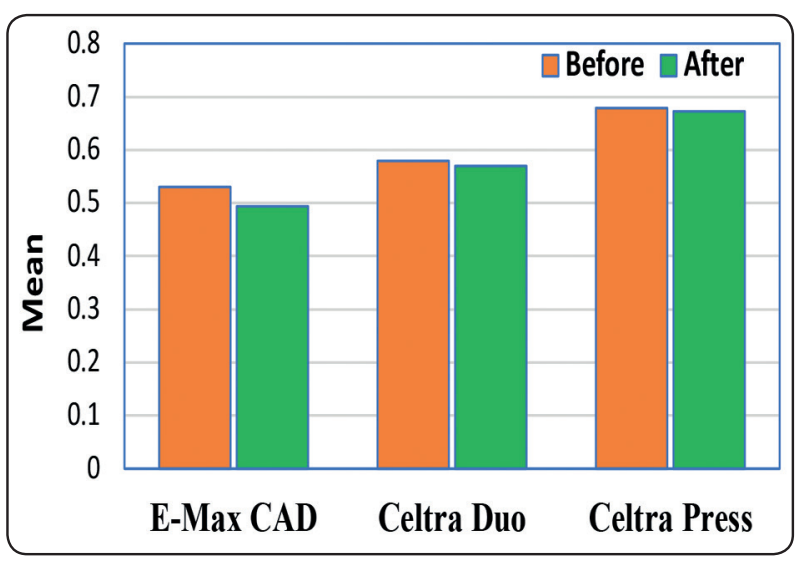

Fig. (2) Bar chart showing mean values of weight for experimental material groups before and after wear simulation.

IPS E-max CAD revealed the highest amount of weight loss, followed by Celtra Duo, while Celtra Press demonstrated the least amount of weight loss. The difference between groups was statistically nonsignificant as indicated by ANOVA test $(\mathrm{p}=0.237$ $>0.05$ ). The change in weight was non-significant as demonstrated by paired t-test for each group.

\section{Roughness changes:}

The mean values and standard deviations (SD) for wear measured by roughness average (Ra measured in $\mu \mathrm{m}$ ) recorded on all materials before and after 3 months wear simulation cycles summarized in table (3) and graphically represented in figure (3).

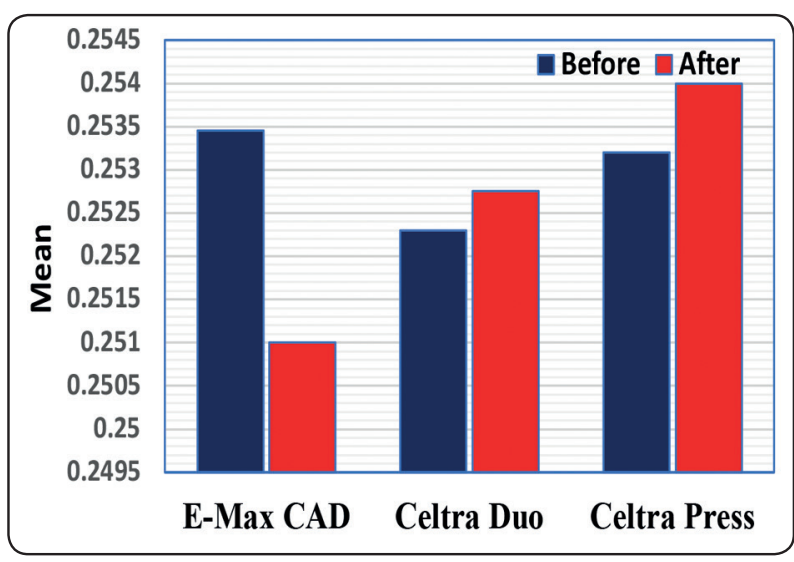

Fig. (3) Bar chart showing mean values of Roughness for experimental material groups before and after wear simulation.

It was found that the highest roughness change was recorded for Celtra Press group mean value, followed by Celtra Duo group, while the lowest roughness change was recorded for E.max CAD group. The difference between groups was statistically significant as indicated by ANOVA test $(\mathrm{p}=0.0243>0.05)$. Tukey's post-hoc showed no significant difference $(\mathrm{p}>0.05)$ between celtra Duo and celtra press.

For E-max CAD group; it was found that the roughness mean value was decreased after wear simulation. The change in roughness was significant as demonstrated by paired t-test $(\mathrm{p}=0.032<0.05)$. While it was found that the roughness mean value

TABLE (3) Wear results (Mean values \pm SD) by roughness change parameter (Ra) for experimental material groups before and after wear simulation

\begin{tabular}{|c|c|c|c|c|c|c|c|}
\hline \multirow{2}{*}{\multicolumn{2}{|c|}{ Material group }} & \multirow{3}{*}{$\begin{array}{c}\text { Mean } \\
0.25345\end{array}$} & \multirow{3}{*}{$\begin{array}{c} \pm \text { SD } \\
\pm 0.002\end{array}$} & \multicolumn{2}{|c|}{ Paired difference } & \multirow{2}{*}{ Changes \% } & \multirow{2}{*}{$\begin{array}{c}\text { T-test } \\
\text { P value }\end{array}$} \\
\hline & & & & Mean & SD & & \\
\hline E-Max & Before & & & \multirow{2}{*}{$-0.00245 \mathrm{a}$} & \multirow{2}{*}{ \pm 0.003} & \multirow{2}{*}{0.955} & \multirow{2}{*}{$0.032 *$} \\
\hline CAD & After & 0.2510 & \pm 0.002 & & & & \\
\hline \multirow{2}{*}{ Celtra Duo } & Before & 0.2523 & \pm 0.001 & \multirow{2}{*}{$0.00045 \mathrm{~b}$} & \multirow{2}{*}{ \pm 0.002} & \multirow{2}{*}{0.188} & \multirow{2}{*}{$0.444 \mathrm{~ns}$} \\
\hline & After & 0.25275 & \pm 0.001 & & & & \\
\hline \multirow{2}{*}{ Celtra Press } & Before & 0.2532 & \pm 0.002 & \multirow{2}{*}{$0.00077 \mathrm{~b}$} & \multirow{2}{*}{ \pm 0.003} & \multirow{2}{*}{0.306} & \multirow{2}{*}{$0.351 \mathrm{~ns}$} \\
\hline & After & 0.2540 & \pm 0.002 & & & & \\
\hline ANOVA & P value & \multicolumn{6}{|c|}{$0.0243^{*}$} \\
\hline
\end{tabular}


was increased after wear for either Celtra Duo or Celtra Press groups. The change in roughness for each was non-significant as demonstrated by paired t-test.
Optical profilometry describes three-dimensional colored scaled images for surface roughness of the tested material groups before and after 3 months wear simulation as shown in Figures (4,5 and 6).

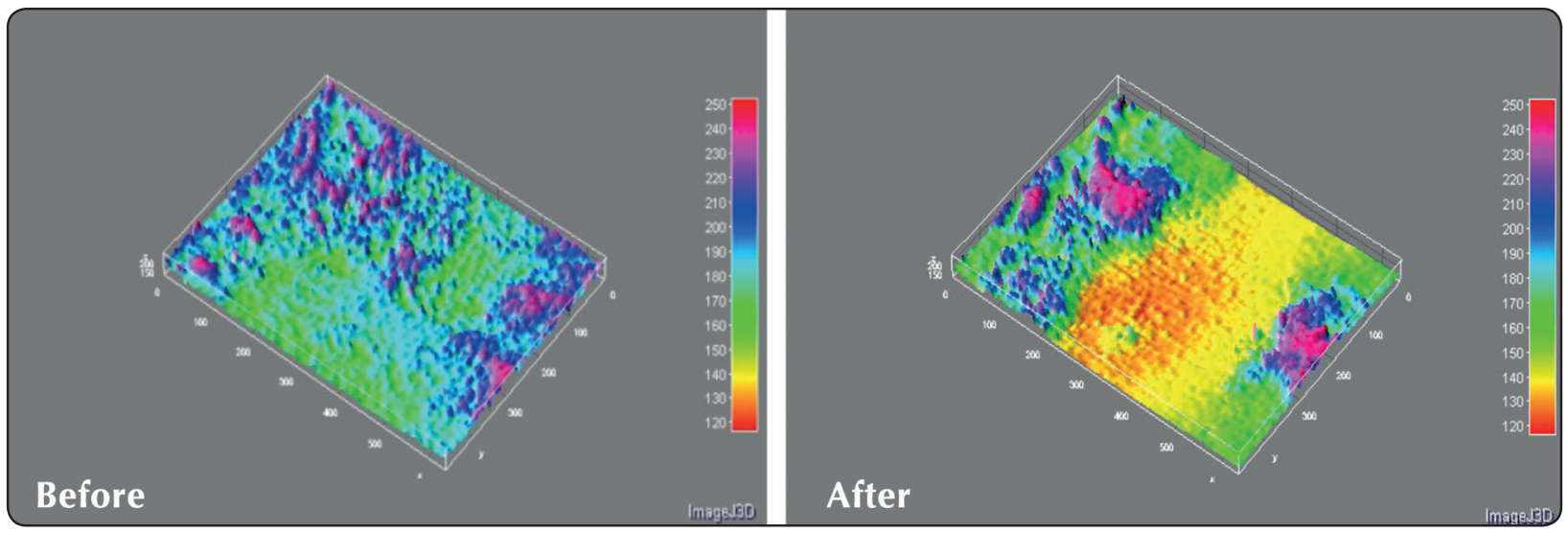

Fig. (4) Representative 3D image showing surface topographic features of E-max sample before and after wear simulation.

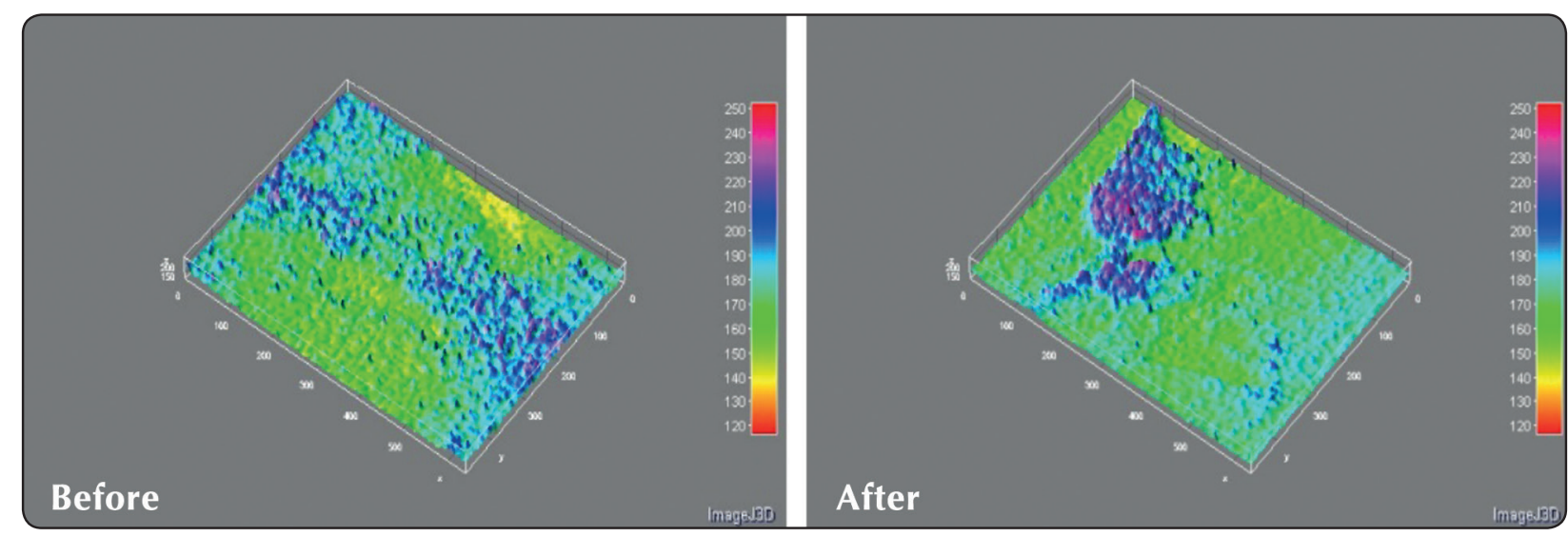

Fig. (5) Representative 3D image showing surface topographic features of Celtra Duo sample before and after wear simulation.

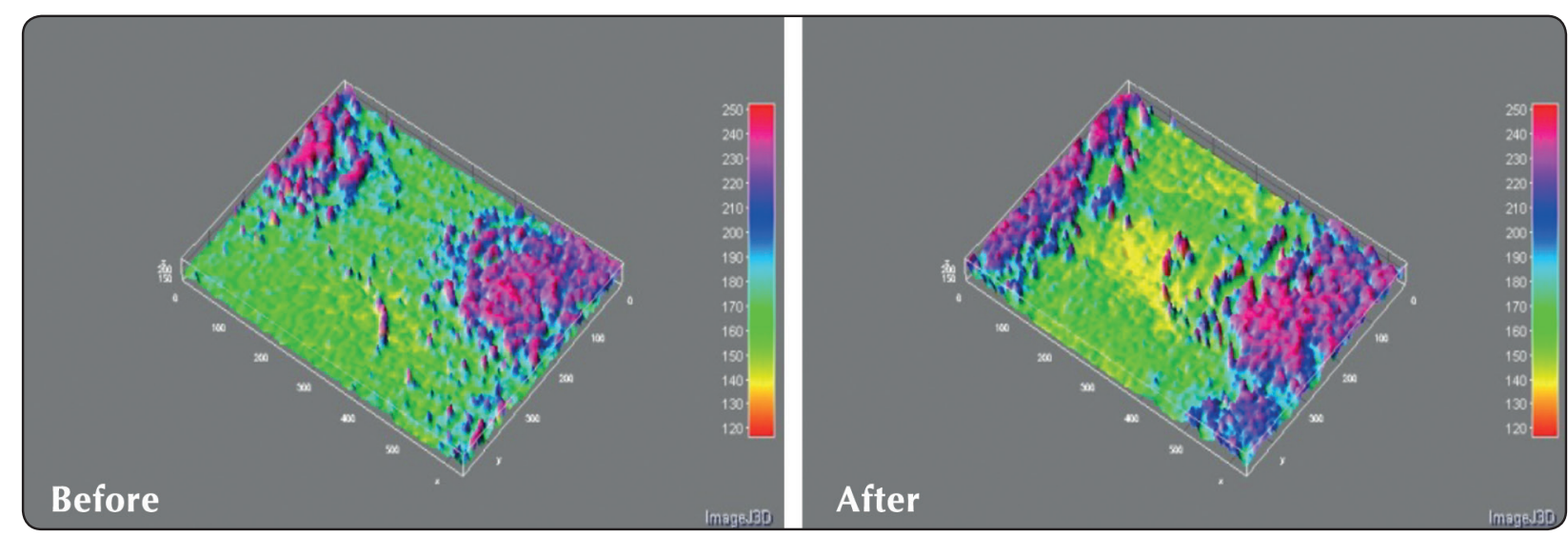

Fig. (6) Representative 3D image showing surface topographic features of Celtra Press sample before and after wear simulation. 


\section{DISCUSSION}

Due to their high esthetic quality, monolithic glass ceramic materials have been used extensively in the construction of veneers, inlays, onlays, crowns, and partial dentures. Furthermore, they eliminate chipping or fracture problem of veneering porcelain ${ }^{(17)}$. However, these monolithic restorations are in direct contact with their antagonists, which may be natural teeth or restorations. So, it is important to study their wear resistance and surface roughness.

In this study, lithium disilicate glass ceramic E-max CAD was chosen as a standard for comparison with ZLS ceramics because of its frequent use in many clinical and laboratory research papers ${ }^{(6,10,18)}$. Two ZLS (Celtra) ceramic materials with different restoration manufacturing techniques and surface finishing were also chosen as the processing method ${ }^{(19)}$ and surface finishing ${ }^{(20)}$ can affect the outcomes.

Wear and surface roughness were evaluated in vitro, which is more practical particularly when a new material was compared. Moreover, their evaluations clinically are time consuming and require skill in patient selection, data collection and analysis (21). Many in vitro testing methods are available for wear evaluation of dental materials (e.g., Pin on disc tribometer, toothbrush simulator, Scratch test) ${ }^{(22)}$. In the present study, a programmable controlled chewing simulator integrated with thermo-cyclic device was used. It simulates 2-body wear testing where each ceramic sample was in direct contact to enamel antagonist in the presence of humidity. Since wear results in material loss, as indicated by several reports, it was assessed by measuring the sample weight before and after wear. ${ }^{23,24)}$. This methodology is an attempt to simulate the clinical situations and was reported in many studies ${ }^{(25,26,27)}$.

The results of this study revealed that IPS E-max CAD had the highest wear after wear simulation. The less wear of Celtra ZLS groups compared to E-max CAD could be attributed to the presence of
$10 \%$ zirconia in the lithium silicate content, so the strength of ZLS was higher than those for lithium disilicate ${ }^{(28)}$. The glassy matrix of $\mathrm{E}$ max CAD had broken and worn-out due to its lower strength compared with the crystals in the crystalline phase. These brittle crystals act as asperities which cause wear to the antagonistic enamel and fracture during wear test ${ }^{(29)}$. The process was repeated and accompanied by weight loss. However, Ling Wang et $\boldsymbol{a l}$ found that wear of polished IPS E-max was lower than the glazed one ${ }^{(30)}$. In this study, E-max CAD samples were polished to obtain the optimum smooth surface texture finishing. This may explain that the E-max CAD group showed no statistically significant difference in weight change before and after wear simulation.

All material groups were fired after surface finishing according to their respective manufacturer's instructions to improve their mechanical properties ${ }^{(9,10,12)}$. Belli et al reported that the Young modulus of both lithium disilicate (IPS E-max CAD) and ZLS (Celtra) materials were similar regardless of the differences in their composition and microstructure ${ }^{(31)}$. So, the high mechanical properties besides the resemblances in young's modulus may explain the non-significant differences in wear between E-max CAD and Celtra ZLS groups. The results agreed with Lawson et al who also found no statistical difference between the wear generated for both lithium disilicate and ZLS materials ${ }^{(32)}$. They referred the insignificant weight loss of ZLS was due to their higher hardness and lower elastic modulus. Compared with lithium disilicate.

Moreover, Stawarczyk et al reported that the insignificant wear of Celtra press was due to its improved flexural strength through Power Firing ${ }^{(9)}$. As well, D'Arcangelo et al found that the minor wear of Celtra duo may be due to strengthening of the material by firing cycle ${ }^{(12)}$. They explained that any defects created during milling were healed at an elevated temperature of firing. 
Surface roughness is considered an important issue for the wear property of ceramic material itself and with the opposing surface. So, the ceramic restorative material that results in less roughness is preferred (26). Wear was quantified by roughness measurement. The optical profilometry was used to detect surface roughness as it tends to fulfill the need for quantitative description of surface topography without contact ${ }^{(33)}$.

In this study, the samples of E-max CAD were polished and both Celtra Press and Celtra Duo were glazed. The E-max CAD group recorded a statistically significant lower roughness change compared to Celtra groups after thermo-mechanical chewing simulation. These results were agreed with Vasiliu et al findings which revealed that lithium disilicate glass-ceramic was rarely affected by thermocycling. Furthermore, its surface polishing resulted in lower roughness compared to the glazed Celtra groups ${ }^{(34)}$. The roughness mean value of E-max CAD group was decreased significantly after wear simulation with enamel antagonist, which may be due to the polished surface together with the high hardness of E-max CAD. The result was confirmed with Amer et al who found that lithium disilicate became smoother with the opposing enamel after the wear simulation cycle ${ }^{(35)}$.

On the other hand, the mean roughness value was increased after wear simulation by thermo-mechanical aging for either Celtra Duo or Celtra Press groups. Both two groups are nearly the same material composition and they were glazed before firing. Thermocycling accompanied the wear simulation test did not maintain the uniform aspect of the glazed surface resulting in some defects ${ }^{(34)}$. According to the study of Alp and Subaşı, the surface roughness was increased with aging of the ZLS glass-ceramic and the type of surface finishing significantly affected the surface roughness ${ }^{(20)}$. However, the crystal size of milled Celtra Duo is smaller than that of heat pressed Celtra Press ceramic. The smaller the crystal size of the ZLS material, the more resistant to be removed by thermo-cycling accompanied with wear simulation ${ }^{(19)}$. This may explain that Celtra Duo recorded non-significant less roughness change than Celtra press after wear simulation.

However, the ZLS construction method did not have a significant impact on either wear or roughness after wear simulation, as the results of this study showed that there was no significant difference between the mean values of the Celtra press and the Celtra Duo ZLS material.

\section{CONCLUSIONS}

Based on the findings of this in vitro study, it could be concluded that:

- ZLS Celtra ceramic had insignificant less wear with enamel antagonist compared to E-max CAD ceramic.

- E-max CAD ceramic had a significantly lower roughness change compared to ZLS Celtra ceramics.

- The surface finishing of glass ceramics can be correlated with their wear and roughness.

- The construction method of ZLS restorative material had no significant effect on both wear and surface roughness.

\section{REFERENCES}

1. Z.R. Zhou, J. Zheng. Tribology of dental materials: a review, J. Phys. D: Appl. Phys. 2008; 41: 3001-22.

2. Lambrechts P, Braem M, Vuylsteke-Wauters M, Vanherle G. Quantitative in vivo wear of human enamel. J Dent Res. 1989; 68:1752-4.

3. Okeson JP. Management of Temporomandibular Disorders and Occlusion. St. Louis: Mosby; 1989. p. 259- 60.

4. Makhija SK, Lawson NC, Gilbert GH, Litaker MS, McClelland JA, Louis DR, et al. Dentist material selection for single-unit crowns: findings from the National Dental Practice-Based Research Network. J Dent. 2016; 55: 40-7.

5. Sadowsky SJ. An overview of treatment considerations for esthetic restorations: a review of the literature. J Prosthet Dent. 2006; 96: 433-42. 
6. Lien W, Roberts H, Plat JA, Vandewalle K, Hill T, Chu T. Microstructural evolution and physical behavior of a lithium disilicate glass-ceramic. Dent Mater J 2015; 31:55-67.

7. Pollington $\mathrm{S}$. Novel glass-ceramics for dental restorations. J Contemp Dent Pract. 2011;12: 60-7.

8. Rosentritt M, Preis V, Behr M, Hahnel S, Handel G and Kolbeck C. Two-body wear of dental porcelain and substructure oxide ceramics Clin. Oral Investig. 2011; 7: 1-9.

9. Stawarczyk B, Dinse L, Eichberger M et al. Flexural strength, fracture toughness, three-body wear, and Martens parameters of pressable lithium-X-silicate ceramics. Dent Mater 2020; 36: 420-30.

10. Reich S, Fischer S, and Sobotta B et al: A preliminary study on the short-term efficacy of chairside computeraided design/ computer assisted manufacturing- generated posterior lithium disilicate crowns. Int. J Prosthod. 2010; 23: 214-6.

11. Elsaka S, Elnaghy A. Mechanical properties of zirconia reinforced lithium silicate glass-ceramic. Dent Mater. 2016; 32(7): 908-14

12. D'Arcangelo C, Vanini L, Rondoni GD, De Angelis F. Wearproperties of dental ceramics and porcelains compared with human enamel. J Prosthet Dent. 2016; 115: 350-5.

13. Naumova EA, Schneider S, Arnold WH, Piwowarczyk A. Wear Behavior of Ceramic CAD/CAM Crowns and Natural Antagonists. Materials (Basel). 2017 Feb 28;10(3): 244.

14. Janyavula S, Lawson N, Cakir D, et al. The wear of polished and glazed zirconia against enamel. J Prosthet Dent. 2013; 109: 22-29.

15. Kakaboura A, Fragouli M, Rahiotis C, et al. Evaluation of surface characteristics of dental composites using profilometry, scanning electron, atomic force microscopy and gloss-meter. J Mater Sci Mater Med. 2007; 18: 155-63.

16. Nawafleh N, Hatamleh M, Elshiyab S and Mack F, Lithium Disilicate Restorations Fatigue Testing Parameters: A Systematic Review. J Prosthod. 2016; 25: 116-26.

17. Quinn GD, Hoffman K, Quinn JB. Strength and fracture origins of a feldspathic porcelain. Dent Mater. 2012; 28: 502-11.

18. Zarone F, Di Mauro MI, Ausiello P, Ruggiero G, Sorrentino R. Current status on lithium disilicate and zirconia: a narrative review. BMC Oral Health. 2019 Jul 4;19(1):134.
19. Vasiliu RD, Porojan SD, Bîrdeanu MI, Porojan L. Effect of Thermocycling, Surface Treatments and Microstructure on the Optical Properties and Roughness of CAD-CAM and Heat-Pressed Glass Ceramics. Materials (Basel). 2020 Jan $14 ; 13(2): 381$.

20. Alp G, Subaşı GM. Effect of Surface Finishing Methods and Aging on Surface Roughness and Optical Properties of Zirconia-Reinforced Lithium Silicate Glass-Ceramic. Cumhuriyet Dent J. 2019; 22:1:121-30.

21. Heintze SD, Cavalleri A, Forjanic M, Zellweger G, Rousson V. A comparison of three different methods for the quantification of the in vitro wear of dental materials. Dent Mater. 2006; 22(11):1051-62.

22. Morozova Y, Holik P, Ctvrtlik R, Tomastik J, Azar B, Sedlata Juraskova E, Harcekova A. Methods of Wear Measuring in Dentistry. J of Dental and Medical Sciences. 2016; 15(6): 63-8.

23. Adriana Claudia. New resistance of pressable low fusing ceramic opposed by dental alloys. J of mechanical Behavior Of biomedical material. 2014; 32: 46-51.

24. Prakki A, Cilli R, de Araújo PA, Navarro MF, Mondelli J, Mondelli RF. Effect of toothbrushing abrasion on weight and surface roughness of $\mathrm{pH}$-cycled resin cements and indirect restorative materials. Quintessence Int. 2007 Oct;38(9): e544-54.

25. Hamza GE, Salem HN, Samman MA. Evaluation of twobody wear rate and roughness of polyetheretherketone and zirconia opposing enamel structure: an in-vitro study. J Arab Soc Med Res. 2019; 14:73-81.

26. Hamed WM, Anwar E, Adel R, Aboushahba M, Abdeen MF, Dagal RS, Rizq MH. Surface roughness of two different monolithic materials after chewing simulation. J Int Oral Health. 2020;12, Suppl S1: 47-52.

27. Suad MH, Nevin AG. Two-body wear and surface roughness of three different ceramic systems and their enamel antagonist. An in vitro study. Al-Azhar Dent J 2017; 4: 347-57.

28. Chen, X.-P.; Xiang, Z.-X.; Song, X.-F.; Yin, L. Machinability: Zirconia-reinforced lithium silicate glass ceramic versus lithium disilicate glass ceramic. J. Mech. Behav. Biomed. Mater. 2020; 101; 103435.

29. Preis V, Behr M, Handel G, Schneider-Feyrer S, Hahnel S, Rosentritt M. Wear performance of dental ceramics after grinding and polishing treatments. Journal of the Mech. Behav. Biomed. Mater. 2012; 10:13-22. 
30. Lin Wang A., Yihong Liu A., Wenjie Si B., Hailan Feng A., Yongqing Tao A., Zhizuo Mac. Friction and wear behaviors of dental ceramics against natural tooth enamel. J of the European Ceramic Society. 2012; 32: 2599-606.

31. Belli R, Wendler M, de Ligny D, Cicconi MR, Petschelt A, Peterlik H, et al. Chairside CAD/CAM materials. Part 1: Measurement of elastic constants and microstructural characterization. Dent Mater. 2017; 33: 84-98.

32. Lawson NC, Bansal R, Burgess JO. Wear, strength, modulus and hardness of CAD/CAM restorative materials. Dent Mater. 2016 Nov; 32(11): e275-e283.
33. Abouelatta OB. 3D surface roughness measurement using a light sectioning vision system. Proc World Cong Eng. 2010: 698-703.

34. Vasiliu R-D, Porojan S-D, Bîrdeanu M-I, Uțu I-D, Porojan L. The Effect of Thermocycling and Surface Treatments on the Surface Roughness and Microhardness of Three HeatPressed Ceramics Systems. Crystals. 2020; 10(3):160.

35. Amer R, Kürklü D, Johnston W. Effect of simulated mastication on the surface roughness of three ceramic systems. J Prosthet Dent. 2015 Aug; 114(2): 260-5. 